\title{
Density of Musashi-1-positive stem cells in the stomach of patients with irritable bowel syndrome
}

\author{
MAGDY EL-SALHY ${ }^{1-3}$, TRYGVE HAUSKEN ${ }^{2,3}$ and JAN GUNNAR HATLEBAKK ${ }^{2,3}$ \\ ${ }^{1}$ Section for Gastroenterology, Department of Medicine, Stord Hospital, 5416 Stord; ${ }^{2}$ Department of Clinical Medicine, \\ University of Bergen, 5020 Bergen; ${ }^{3}$ National Centre for Functional Gastrointestinal Disorders, 5021 Bergen, Norway
}

Received December 27, 2019; Accepted May 28, 2020

DOI: $10.3892 / \mathrm{mmr} .2020 .11412$

\begin{abstract}
Irritable bowel syndrome (IBS) affects $\sim 12 \%$ of the global population. Although the etiology of IBS is not completely understood, several factors are known to serve a pivotal role in its pathophysiology, including genetic factors, diet, the intestinal microbiota, gastrointestinal endocrine cells and low-grade inflammation. Musashi-1 is expressed by stem cells and their early progeny, and is used as a stem cell marker. The low density of intestinal endocrine cells in patients with IBS is thought to be caused by decreased numbers of intestinal stem cells and their differentiation into enteroendocrine cells. The present study employed Musashi-1 as a marker to detect stem cells in the stomach of 54 patients with IBS and 51 healthy subjects. The patients and controls underwent standard gastroscopy, and biopsy samples were taken from the corpus and antrum. Immunohistochemical staining of gastrin, somatostatin and Mushasi-1 was carried out and semi-quantified by computerized image analysis. The density (number of positive cells $/ \mathrm{mm}^{2}$ epithelium) of gastrin-positive cells in the controls and patients with IBS were $337.9 \pm 560$ and $531.0 \pm 908$ (median \pm range; $\mathrm{P}<0.0001$ ), respectively. For somatostatin-positive cells, the density reached $364.4 \pm 526.0$ in the healthy controls and $150.7 \pm 514.0$ in patients with IBS $(\mathrm{P}<0.0001)$. The density of Musashi-1-positive cells was defined as the number of cells per gastric or pyloric gland neck. In the corpus, Musashi-1-positive cells density reached 3.0 \pm 7.0 in the corpus of the healthy controls and 3.8 \pm 7.7 in the patients with IBS. Moreover, the corresponding values in the antrum were $6.0 \pm 6.0$ and $6.0 \pm 6.0$, respectively. The Musashi-1-positive cell density did not differ significantly between the controls and patients with IBS in the corpus or antrum $(\mathrm{P}=0.4$ and 0.3 , respectively). These findings indicated that changes in the stomach endocrine cells observed in patients with IBS may not be explained by an abnormality in stem cells like those found in the small and large intestines of these patients.
\end{abstract}

Correspondence to: Professor Magdy El-Salhy, Section for Gastroenterology, Department of Medicine, Stord Hospital, Tysevegen 64, 5416 Stord, Norway

E-mail: magdy.el-salhy@helse-fonna.no

Key words: computerized image analysis, endocrine cells, immunohistochemistry, gastroscopy, stem cells

\section{Introduction}

Irritable bowel syndrome (IBS) is a common gastrointestinal disorder with unclear pathophysiology $(1,2)$. However, several factors are known to contribute to the pathophysiology of this condition, including genetic factors, diet, the intestinal microbiota, enteroendocrine cells and low-grade inflammation (1-4).

Gastrointestinal endocrine cells produce $>10$ different hormones that regulate several functions of the gastrointestinal tract, such as gastrointestinal motility, visceral sensitivity, absorption, secretion, proliferation, local immune defense and appetite $(1,5)$. The gastrointestinal endocrine cells interact and integrate with each other, and with the enteric, autonomic and central nervous systems (6). In IBS, gastrointestinal motility and secretion are abnormal and patients exhibit visceral hypersensitivity (5). The density of enteroendocrine cells in patients with IBS has been reported to be lower than healthy subjects, which may contribute to the pathophysiology of IBS (2,5,7-15).

Previous studies have suggested that the intestinal density of Musashi-1- and neurogenin-3-positive cells were reduced in patients with IBS $(7,13,16)$. Musashi-1 is a marker for intestinal stem cells and their early progeny (17-21). Neurogenin-3 is expressed by an early progenitor for endocrine cells $(22,23)$. It has been proposed that the low density of enteroendocrine cells seen in patients with IBS could be caused by this abnormality in stem cells and their differentiation into enteroendocrine cells $(6,7,9-13,16,24-26)$. Furthermore, the role of genetic factors, diet, intestinal microbiota, enteroendocrine cells and low-grade inflammation in the pathophysiology of IBS is likely mediated through intestinal stem cells (27).

The density of endocrine cells in the stomach corpus is similar in patients with IBS and healthy subjects $(28,29)$. However, the density of gastrin-positive cells in the stomach antrum has been reported to be higher, whereas the density of somatostatin-positive cells has been reported to be lower in patients with IBS, compared with healthy subjects (30). These differences may explain the high incidence of erosive esophagitis observed in patients with IBS (31), as gastrin stimulates acid secretion and somatostatin inhibits acid secretion (6).

The aim of the present study was to investigate whether the changes in the density of gastrin- and somatostatin-positive in the stomach of patients with IBS were associated with alterations in stem cells. 


\section{Materials and methods}

Patients and controls. Patients with IBS ( $\mathrm{n}=54)$, according to the Rome IV criteria (32), were recruited from an outpatient clinic at Stord Hospital (Stord, Norway). A control group was formed from healthy subjects $(n=51)$ without any gastrointestinal complaints recruited through an announcement in the local newspaper. The controls comprised 38 females and 13 males with a mean age of 38 years (range, 20-67 years).The characteristics of the patients with IBS are provided in Table I. Co-existence of other functional gastrointestinal disorders was not recorded in the patients with IBS included in the study. The present study was approved by The Regional Committee for Medical and Health Research Ethics West (approval no. 2017/1197/REK Vest). All participants gave oral and written consent to participate.

Gastroscopy and histopathology. Both the patients and controls underwent standard gastroscopy after an overnight fast. Three biopsy samples were taken from the antrum and three from the corpus (major curvature) of the stomach. Two additional biopsies were taken from the antrum and analyzed in a rapid urease test for Helicobacter pylori (HelicotecUT Plus, Strong Biotech Corp.). The two biopsy samples were placed in polystyrene gel containing urea substrate for $1 \mathrm{~h}$ at room temperature. In the presence of Helicobacter pylori urease hydrolysis urea to produce ammonia and $\mathrm{CO}_{2}$, which changes the $\mathrm{pH}$ and is detected as a change in the color of the gel from yellow to red. The biopsy samples were fixed in $4 \%$ buffered paraformaldehyde at room temperature overnight, embedded in paraffin wax, then cut into $5-\mu \mathrm{m}$ sections that were stained with hematoxylin for $20 \mathrm{sec}$ and eosin at room temperature for 3-4 min and were examined under a light microscope (Olympus BX43, Olympus Corporation).

Immunohistochemistry and computerized image analysis. The sections were immunostained using the avidin-biotin-complex (ABC) method with the Vectastain ${ }^{\circledR}$ Elite ABC-HRP kit (cat. no. PK-6200, Vector Laboratories, Inc.). The sections were incubated for $20 \mathrm{~min}$ with the blocking normal horse serum then with the primary antibodies at room temperature overnight. The sections were incubated with the secondary biotinylated horse anti-rabbit IgG antibody for $30 \mathrm{~min}$ at room temperature followed by the Avidin-bioytin complex for $30 \mathrm{~min}$ at room temperature. The following polyclonal rabbit primary antibodies were used: Anti-human gastrin-17 (cat. no. IR519; 1:500; Dako; Agilent Technologies, Inc.); anti-synthetic cyclic (amino-acid sequence 1-14) somatostatin (cat. no. A0566; 1:200; Dako; Agilent Technologies, Inc.); and an antibody raised against a synthetic peptide derived from human Musashi-1 (amino acids 1-100; internal sequence) conjugated to keyhole limpet haemocyanin (cat. no. ab21628; 1:100; Abcam).

The density of Musashi-1-positive cells was semi-quantified on a computer linked to a BX43 light microscope equipped with a DP26 digital camera using Olympus cellSens imaging software (version 1.7; all from Olympus
Corporation). The number of Musashi-1-immunoreactive cells, and the number of gastric or pyloric gland necks in each field were counted manually by pointing and clicking the computer mouse in ten randomly chosen fields. A x400 magnification was used and each field on the monitor represented a tissue area of $0.14 \mathrm{~mm}^{2}$. The data from the fields were tabulated, and the cell density was expressed as the number of cells per gastric or pyloric gland neck. The number of gastrin- or somatostatin-immunoreactive cells, and the area of epithelial cells were measured using the same system in 10 randomly chosen fields. The density of gastrin- and somatostatin-positive cells were expressed as number of cells $/ \mathrm{mm}^{2}$ epithelium. Immunostained sections from the patients with IBS and controls were coded and mixed, with measurements made by an investigator who was blind to the identity of the sections.

Statistical analysis. The $\chi^{2}$ test was used to assess differences between the patients and controls with regards to sex and the incidence of $H$. pylori infection. Differences in age, and in the densities of gastrin-, somatostatin-, and Musashi-1-positive cells were tested using the Mann-Whitney nonparametric test. The statistical analyses were performed using GraphPad Prism software (version 8; GraphPad Software, Inc.). $\mathrm{P}<0.05$ was considered to indicate a statistically significant difference.

\section{Results}

Patients and controls. The sex and age distributions did not differ significantly between the patients with IBS and the controls $(\mathrm{P}=0.9$ and 0.8 , respectively). The urease test and histopathological examination indicated $H$. pylori infection in three patients and two controls, also with no significant difference between the groups $(\mathrm{P}=0.6$; Table I).

Gastroscopy and histopathology. Gastroscopy suggested that the esophagus, stomach and duodenum were all macroscopically normal in both groups. A histopathological examination of the corpus and antrum indicated normal histology, with the exception of individuals with $H$. pylori infection, in whom metaplasia was found in the antrum.

Immunohistochemistry and computerized image analysis. The gastrin-positive cell density in the controls and patients with IBS were 303.0 \pm 560.0 and $623.0 \pm 668.0$ (median \pm range; $\mathrm{P}<0.0001$ ), respectively (Fig. 1). The corresponding figures for somatostatin-positive cell density were 302.0 \pm 526.0 and 140.0 \pm 514.0 ( $\mathrm{P}<0.0001$; Fig. 2).

Musashi-1-immunoreactive cells were concentrated at the necks of the gastric glands of the corpus and of the pyloric glands of the antrum, where they were evident mostly in a clonogenic proliferation or differentiation form (Fig. 3). The density of Musashi-1-positive cells in the corpus was $6.0 \pm 6.0$ in the controls and $6.0 \pm 6.0$ in the patients with IBS $(\mathrm{P}=0.4)$; the corresponding values in the antrum were 3.0 07.0 and, 3.8 \pm 7.7 respectively ( $\mathrm{P}=0.3$; Fig. 4). A subgroup analysis based on the phenotype of the disorder (diarrhea predominant, constipation predominant or mixed type) was not performed, as the number of patients in these subgroups was too small to allow reliable analysis. 
Table I. Characteristics of the controls and patients with IBS.

\begin{tabular}{lcc}
\hline Clinicopathological variable & Control group, $\mathrm{n}=51$ & IBS group, $\mathrm{n}=54$ \\
\hline Age, mean (range) years & $36(20-64)$ & $32(18-52)$ \\
Sex, $\mathrm{n}$ & & 41 \\
Male & 10 & 10 \\
Female & & 20 \\
IBS subtype, $\mathrm{n}$ & 0 & 21 \\
IBS-D & 0 & 13 \\
IBS-C & 0 & $15.5 \pm 8.0$ \\
IBS-M & 0 & 3 \\
IBS duration, years (mean \pm SD) & 2 & \\
H. pylori infection & & $53(98.2)$ \\
Medication, $\mathrm{n}(\%)$ & $2(3.9)$ & $42(77.8)$ \\
PPI medication & $32(62.8)$ & $2(3.7)$ \\
Birth control medication & $0(0.0)$ & $3(5.6)$ \\
Antimigraine medication & $0(0.0)$ & $1(1.9)$ \\
Medication against asthma/allergies & $0(0.0)$ & $0(0.0)$ \\
Medication with laevothyroxine & $1(2.0)$ & \\
Medication with heart/vascular drugs & & \\
\hline
\end{tabular}

IBS, irritable bowel syndrome; PPI, proton pump inhibitor; D, diarrhea predominant; C, constipation predominant; M, mixed type.
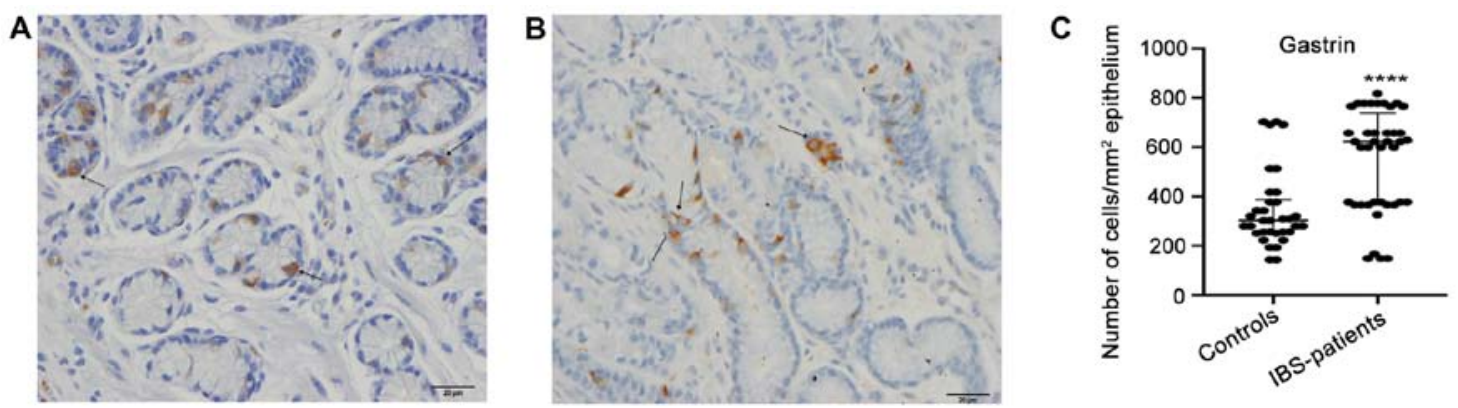

Figure 1. Gastrin-positive-cells (arrows) in (A) a healthy control and in (B) a patient with IBS. (C) Densities of gastrin immunoreactive cells in the epithelium of patients with IBS and healthy controls. Scale, $20 \mu \mathrm{m}$. ${ }^{* * * * *} \mathrm{P}<0.0001$. Data are presented as the median and interquartile range. IBS, irritable bowel syndrome.
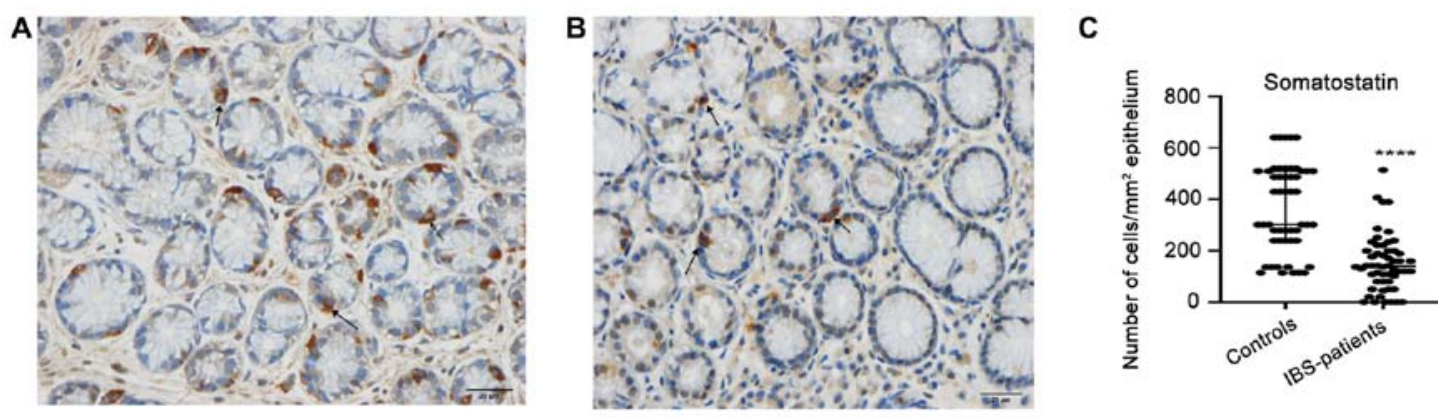

Figure 2. Somatostatin-positive-cells (arrows) in (A) a healthy control and in (B) a patient with IBS. (C) Densities of somatostatin-immunoreactive cells in the epithelium of patients with IBS and healthy controls. Scale, $20 \mu \mathrm{m} .{ }^{* * * * *} \mathrm{P}<0.0001$. Data are presented as the median \pm interquartile range. IBS, irritable bowel syndrome.

\section{Discussion}

The stomach is divided anatomically into the corpus and antrum, each comprising different cells and functions (33).
The gastric glands of the corpus contain mucous neck cells, parietal cells, chief cells and endocrine cells. In the antrum, endocrine cells and mucous cells are the main cell types in the pyloric glands $(33,34)$. While serotonin- and 

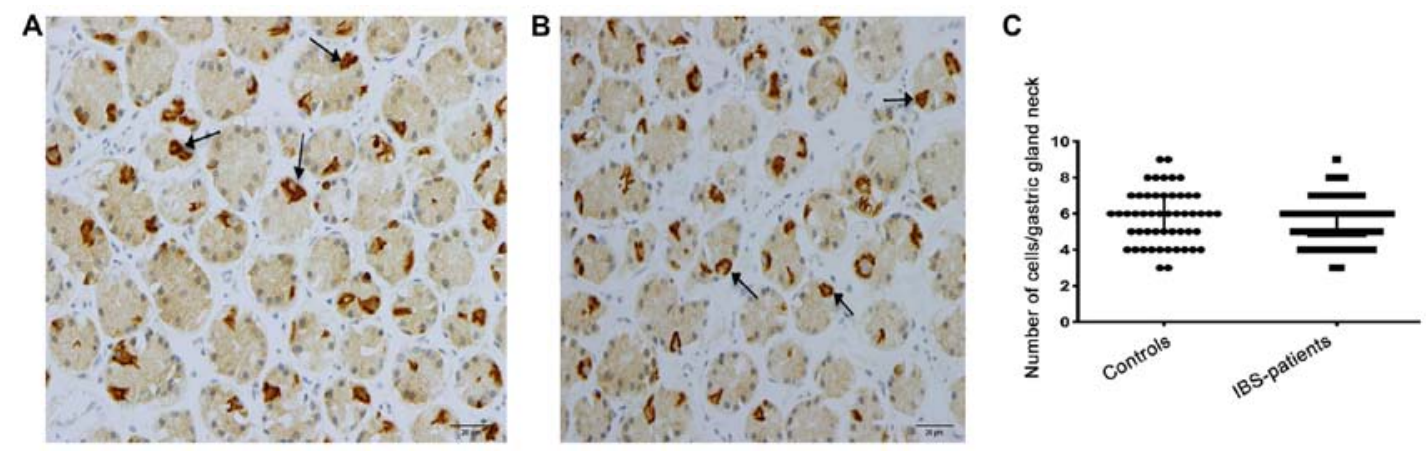

Figure 3. Musashi-1-positive cells (arrows) in the necks of the gastric glands of the corpus in (A) a patient with irritable bowel syndrome and (B) in a healthy control. (C) Densities of Musashi-1-positive cells in the corpus of patients with IBS and healthy controls. Scale, $20 \mu \mathrm{m}$. Data are presented as the median and interquartile range. IBS, irritable bowel syndrome.
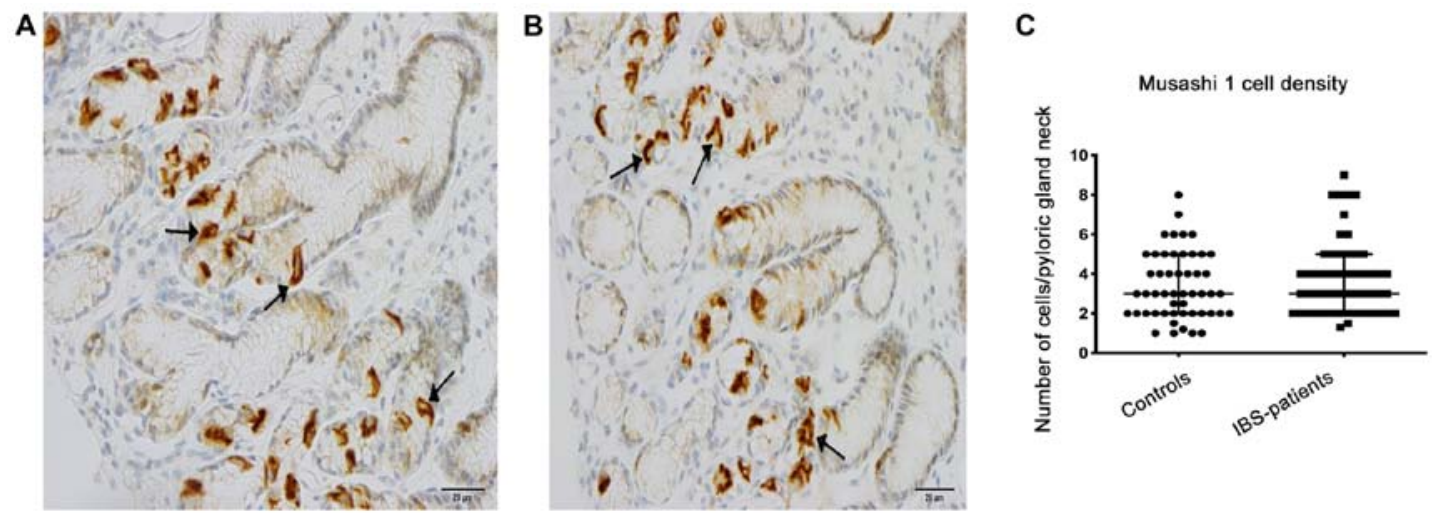

Figure 4. Musashi-1-positive cells (arrows) are present in the necks of the pyloric glands of the antrum. Musashi-1-positive cells in (A) a patient with irritable bowel syndrome and (B) in a healthy control. Densities of Musashi-1-positive cells in the antrum of patients with IBS and healthy controls (C) Scale, $20 \mu \mathrm{m}$. IBS, irritable bowel syndrome.

somatostatin-expressing cells are present in both the corpus and the antrum, ghrelin-positive cells are present only in the oxyntic mucosa of the corpus, while gastrin-positive cells are exclusive to the pyloric glands of the antrum $(28,30)$. Several attempts have been made to identify a specific marker for gastric stem cells (33). Musashi-1, which is considered a marker for intestinal stem cells and their early progeny, is reportedly expressed by cells in the corpus and antrum of the stomach $(35,36)$.

The present study found that Musashi-1-expressing cells were mostly present at the necks of the gastric glands of the corpus and of the pyloric glands of the antrum, which is consistent with previous observations $(35,36)$. The density of Musashi-1-positive cells in both the corpus and antrum did not differ between patients with IBS and healthy controls. These observations may explain why, in a previous study, the total density of endocrine cells detected using chromogranin $\mathrm{A}$ in the corpus and antrum was similar in patients with IBS and healthy controls (29). In addition, the densities of ghrelin-, serotonin- and somatostatin-expressing cells in the oxyntic mucosa of the corpus did not differ between patients with IBS and healthy controls in a previous study (28). However, the densities of gastrin-positive cells were higher and somatostatin-positive cells were lower in the antrum of patients with IBS, compared with healthy controls. These differences could not be explained by abnormalities in stem cells like those previously observed in the small and large intestines of patients with IBS, where density of Musashi-1-positive cells were lower than that of healthy controls $(2,5,37)$.

The mechanisms underlying the changes in the densities of antral gastrin- and somatostatin-positive cells in patients with IBS remain unclear. These changes could represent a response to the changes in the intestinal chromogranin A, serotonin, secretin, cholecystokinin, gastric inhibitory peptide, somatostatin, peptide YY and enteroglucagon (oxyntomodulin) cells seen in these patients $(2,5,7-15)$. The increase in the number of gastrin-expressing cells and the reduction in the number of somatostatin-expressing cells could result from activation of gastrin synthesis and inhibition of somatostatin synthesis, a phenomenon that has been observed in gastrointestinal endocrine cells $(38,39)$. However, the present study was limited to measuring changes in densities of gastrin-, somatostatin- and Musashi-1-expressing cells. The expression or secretion of these active substances were not evaluated.

In conclusion, the changes in the density of antral gastrinand somatostatin-expressing cells in patients with IBS cannot be explained by a low density of stem cells; thus as the gut endocrine cells integrate and interact with each other, the changes in gastrin-and somatostatin-expressing cells in patients with IBS may be caused by the direct changes in the intestinal endocrine cells. 


\section{Acknowledgements}

Not applicable.

\section{Funding}

The study was supported by grants from Helse Fonna (grant no. 40415) and Helse Vest (grant no. 192234).

\section{Availability of data and materials}

The datasets used and/or analyzed during the present study are available from the corresponding author on reasonable request.

\section{Authors' contributions}

MES designed the study, obtained the funding, recruited the patients, performed gastroscopies, collected, analyzed and interpreted the data, and drafted the manuscript. TH and JGH contributed to the design of the study, and to the analysis and interpretation of the data, and critically revised the manuscript for important intellectual content. All authors read and approved the final the manuscript.

\section{Ethics approval and consent to participate}

The present study was approved by The Regional Committee for Medical and Health Research Ethics West, Bergen, Norway (approval no. 2017/1197/REK Vest). Oral and written consent was obtained from all subjects.

\section{Patient consent for publication}

Not applicable.

\section{Competing interests}

The authors declare that they have no competing interests.

\section{References}

1. El-Salhy M: Irritable bowel syndrome: Diagnosis and pathogenesis. World J Gastroenterol 18: 5151-5163, 2012.

2. El-Salhy M: Recent developments in the pathophysiology of irritable bowel syndrome. World J Gastroenterol 21: 7621-7636, 2015.

3. El-Salhy M, Gundersen D, Hatlebakk JG and Hausken T: Irritable bowel syndrome: Diagnosis, pathogenesis and treatment options. Nova Science Publishers, Inc., New York, 2012.

4. El-Salhy M, Hatlebakk JG, Gilja $\mathrm{OH}$ and Hausken T: Irritable bowel syndrome: Recent developments in diagnosis, pathophysiology, and treatment. Expert Rev Gastroenterol Hepatol 8 : 435-443, 2014.

5. El-Salhy M, Gundersen D, Gilja OH, Hatlebakk JG and Hausken T: Is irritable bowel syndrome an organic disorder? World J Gastroenterol 20: 384-400, 2014.

6. El-Salhy M, Seim I, Chopin L, Gundersen D, Hatlebakk JG and Hausken T: Irritable bowel syndrome: The role of gut neuroendocrine peptides. Front Biosci (Elite Ed) 4: 2783-2800, 2012.

7. El-Salhy M and Gilja OH: Abnormalities in ileal stem, neurogenin 3, and enteroendocrine cells in patients with irritable bowe syndrome. BMC Gastroenterol 17: 90, 2017.

8. El-Salhy M, Gilja OH, Gundersen D, Hatlebakk JG and Hausken T: Duodenal chromogranin a cell density as a biomarker for the diagnosis of irritable bowel syndrome. Gastroenterol Res Pract 2014: 462856, 2014
9. El-Salhy M, Gilja OH, Gundersen D, Hatlebakk JG and Hausken T: Endocrine cells in the ileum of patients with irritable bowel syndrome. World J Gastroenterol 20: 2383-2391, 2014.

10. El-Salhy M, Gundersen D, Hatlebakk JG, Gilja OH and Hausken T: Abnormal rectal endocrine cells in patients with irritable bowel syndrome. Regul Pept 188: 60-65, 2014.

11. El-Salhy M, Gundersen D, Ostgaard H, Lomholt-Beck B, Hatlebakk JG and Hausken T: Low densities of serotonin and peptide YY cells in the colon of patients with irritable bowel syndrome. Dig Dis Sci 57: 873-878, 2012.

12. El-Salhy M, Patcharatrakul T, Hatlebakk JG, Hausken T, Gilja OH and Gonlachanvit S: Chromogranin A cell density in the large intestine of Asian and European patients with irritable bowel syndrome. Scand J Gastroenterol 52: 691-697, 2017.

13. El-Salhy M, Patcharatrakul T, Hatlebakk JG, Hausken T, Gilja $\mathrm{OH}$ and Gonlachanvit S: Enteroendocrine, Musashi 1 and neurogenin 3 cells in the large intestine of Thai and Norwegian patients with irritable bowel syndrome. Scand J Gastroenterol 52: 1331-1339, 2017.

14. Dizdar V, Spiller R, Singh G, Hanevik K, Gilja OH, El-Salhy M and Hausken T: Relative importance of abnormalities of CCK and 5-HT (serotonin) in Giardia-induced post-infectious irritable bowel syndrome and functional dyspepsia. Aliment Pharmacol Ther 31: 883-891, 2010.

15. El-Salhy M, Vaali K, Dizdar V and Hausken T: Abnormal small-intestinal endocrine cells in patients with irritable bowel syndrome. Dig Dis Sci 55: 3508-3513, 2010.

16. El-Salhy M, Hatlebakk JG and Hausken T: Reduction in duodenal endocrine cells in irritable bowel syndrome is associated with stem cell abnormalities. World J Gastroenterol 21: 9577-9587, 2015.

17. Montgomery RK and Breault DT: Small intestinal stem cell markers. J Anat 213: 52-58, 2008.

18. Kayahara T, Sawada M, Takaishi S, Fukui H, Seno H, Fukuzawa H, Suzuki K, Hiai H, Kageyama R, Okano H and Chiba T: Candidate markers for stem and early progenitor cells, Musashi-1 and Hes1, are expressed in crypt base columnar cells of mouse small intestine. FEBS Lett 535: 131-135, 2003.

19. Potten CS: Stem cells in gastrointestinal epithelium: Numbers, characteristics and death. Philos Trans R Soc Lond B Biol Sci 353: 821-830, 1998.

20. Barker N, van Oudenaarden A and Clevers H: Identifying the stem cell of the intestinal crypt: Strategies and pitfalls. Cell Stem Cell 11: 452-460, 2012.

21. Potten CS, Booth C and Pritchard DM: The intestinal epithelial stem cell: The mucosal governor. Int J Exp Pathol 78: 219-243, 1997.

22. Lee CS, Perreault N, Brestelli JE and Kaestner KH: Neurogenin 3 is essential for the proper specification of gastric enteroendocrine cells and the maintenance of gastric epithelial cell identity. Genes Dev 16: 1488-1497, 2002.

23. Lee CS and Kaestner KH: Clinical endocrinology and metabolism. Development of gut endocrine cells. Best Pract Res Clin Endocrinol Metab 18: 453-462, 2004.

24. El-Salhy M, Mazzawi T, Gundersen D and Hausken T: Chromogranin A cell density in the rectum of patients with irritable bowel syndrome. Mol Med Rep 6: 1223-1225, 2012.

25. El-Salhy M, Wendelbo I and Gundersen D: Reduced chromogranin A cell density in the ileum of patients with irritable bowel syndrome. Mol Med Rep 7: 1241-1244, 2013.

26. El-Salhy M, Wendelbo I and Gundersen D: Serotonin and serotonin transporter in the rectum of patients with irritable bowel disease. Mol Med Rep 8: 451-455, 2013.

27. El-Salhy M: Possible role of intestinal stem cells in the pathophysiology of irritable bowel syndrome. World J Gastroenterol 26: $1427-1438,2020$.

28. El-Salhy M, Gilja OH, Gundersen D and Hausken T: Endocrine cells in the oxyntic mucosa of the stomach in patients with irritable bowel syndrome. World J Gastrointest Endosc 6: 176-185, 2014.

29. El-Salhy M, Gilja OH and Hausken T: Chromogranin A cells in the stomachs of patients with sporadic irritable bowel syndrome. Mol Med Rep 10: 1753-1757, 2014.

30. El-Salhy M, Gilja OH, Hatlebakk JG and Hausken T: Stomach antral endocrine cells in patients with irritable bowel syndrome. Int J Mol Med 34: 967-974, 2014.

31. El-Salhy M, Gilja OH and Hatlebakk JG: Overlapping of irritable bowel syndrome with erosive esophagitis and the performance of Rome criteria in diagnosing IBS in a clinical setting. Mol Med Rep 20: 787-794, 2019.

32. Longstreth GF, Thompson WG, Chey WD, Houghton LA, Mearin F and Spiller RC: Functional bowel disorders. Gastroenterology 130: 1480-1491, 2006. 
33. Han ME and Oh SO: Gastric stem cells and gastric cancer stem cells. Anat Cell Biol 46: 8-18, 2013.

34. Khurana S and Mills JC: The gastric mucosa development and differentiation. Prog Mol Biol Transl Sci 96: 93-115, 2010.

35. Akasaka Y, Saikawa Y, Fujita K, Kubota T, Ishikawa Y, Fujimoto A, Ishii T, Okano $\mathrm{H}$ and Kitajima M: Expression of a candidate marker for progenitor cells, Musashi-1, in the proliferative regions of human antrum and its decreased expression in intestinal metaplasia. Histopathology 47: 348-356, 2005.

36. Murata H, Tsuji S, Tsujii M, Nakamura T, Fu HY, Eguchi H, Asahi K, Okano H, Kawano S and Hayashi N: Helicobacter pylori infection induces candidate stem cell marker Musashi-1 in the human gastric epithelium. Dig Dis Sci 53: 363-369, 2008.

37. El-Salhy M, Hausken T, Gilja OH and Hatlebakk JG: The possible role of gastrointestinal endocrine cells in the pathophysiology of irritable bowel syndrome. Expert Rev Gastroenterol Hepatol 11: 139-148, 2017.
38. Habib AM, Richards P, Rogers GJ, Reimann F and Gribble FM: Co-localisation and secretion of glucagon-like peptide 1 and peptide YY from primary cultured human L cells. Diabetologia 56: 1413-1416, 2013.

39. El-Salhy M, Hatlebakk JG and Hausken T: Possible role of peptide YY (PYY) in the pathophysiology of irritable bowel syndrome (IBS). Neuropeptides 79: 101973, 2020.

This work is licensed under a Creative Commons Attribution-NonCommercial-NoDerivatives 4.0 International (CC BY-NC-ND 4.0) License. 